\title{
Investigation on NO Oxidation during Ozone Oxidation Denitration of Sintering Flue Gas
}

\author{
Yingxin Yang, Lu Zhong, Jingling Hu, Xueliang Xue, Xiaotu Hu, and Yong Liu \\ Guangdong J-Tech Environment Science Co., Ltd., Guangzhou 510663, China
}

\begin{abstract}
With the intensified requirements on ambient air quality, controlling $\mathrm{NO}_{x}$ emission from sintering flue gas has become the most important priority in steel industry. Ozone oxidation denitration process has become the most closely watched sintering flue gas denitration technology. In order to investigate the influence of different operating conditions on $\mathrm{NO}$ oxidation in practical engineering application of ozone oxidation denitration process, an ozone oxidation system was built, and sintering flue gas was extracted from the pipeline between the induced draft fan and the desulfurization tower. The influence of discharge power and $\mathrm{O}_{2}$ flow rate of ozone generator on $\mathrm{O}_{3}$ concentration, $\mathrm{O}_{3}$ yield and NO oxidation efficiency were investigated. The results indicated that $\mathrm{NO}$ oxidation efficiency increased with the discharge power. And the increase of $\mathrm{O}_{3}$ dosage imposed a significant influence on $\mathrm{NO}$ oxidation efficiency. However, little effect of $\mathrm{O}_{2}$ flow rate on $\mathrm{NO}$ oxidation efficiency was observed.
\end{abstract}

\section{Introduction}

With the intensified requirements on ambient air quality, controlling $\mathrm{NO}_{x}$ emission from sintering flue gas has become the most important priority in steel industry. However, the performance of flue gas denitration technology implemented in steel industry is not satisfactory compared with other air pollution control technologies such as desulfurization.

It is widely acknowledged that $\mathrm{NO}_{x}$ generated by sintering process of steel industry is mainly comprised of NO (95\% vol.) [1] which is difficult to be removed from flue gas due to its stability especially the limited solubility. The solubility can be improved by oxidation where NO is transformed into high-valence nitrogen oxides (such as $\mathrm{NO}_{2}, \mathrm{NO}_{3}, \mathrm{~N}_{2} \mathrm{O}_{5}$, etc.), thus the removal could be readily performed by wet scrubber. As a reactive oxidant, ozone has drawn great attention in oxidation denitration since it exhibits many advantages which are low economic costs, high selectivity to NO, and resistance to temperature fluctuations [2]. In the research conducted by Mok [3], after the exhaust gas passed through the ozonizing chamber and the absorber sequentially, $\mathrm{NO}_{x}$ removal efficiency of about $95 \%$ and $\mathrm{SO}_{2}$ removal efficiency of $100 \%$ were obtained. Similar results were observed by Wang [4] who found that $97 \%$ of $\mathrm{NO}$ and nearly $100 \%$ of $\mathrm{SO}_{2}$ can be removed simultaneously by alkaline washing tower after the injection of ozone.

According to the research results of Wang [5], the oxidation reactions between $\mathrm{O}_{3}$ and $\mathrm{NO}$ could be expressed by equation (1) to (3) where $\mathrm{NO}$ was oxidized into $\mathrm{NO}_{2}$ which further transforms into $\mathrm{N}_{2} \mathrm{O}_{5}$ in the presence of excessive $\mathrm{O}_{3}$.

$$
\begin{aligned}
& \mathrm{O}_{3}+\mathrm{NO} \rightarrow \mathrm{NO}_{2}+\mathrm{O}_{2} \\
& \mathrm{O}_{3}+\mathrm{NO}_{2} \rightarrow \mathrm{O}_{2}+\mathrm{NO}_{3} \\
& \mathrm{NO}_{2}+\mathrm{NO}_{3} \rightarrow \mathrm{N}_{2} \mathrm{O}_{5}
\end{aligned}
$$

As a result, the $\mathrm{O}_{3}$ concentration would not only dominate the performance of $\mathrm{NO}$ oxidation effect, but also play a significant role in the removal of $\mathrm{NO}$ in the whole process of oxidation denitration. In order to investigate the influence of different operating conditions on $\mathrm{NO}$ oxidation in practical engineering application of ozone oxidation denitration process, an ozone oxidation system was built, and sintering flue gas was extracted from the pipeline between the induced draft fan and the desulfurization tower. The influence of discharge power and $\mathrm{O}_{2}$ flow rate of ozone generator on $\mathrm{O}_{3}$ concentration, $\mathrm{O}_{3}$ yield and $\mathrm{NO}$ oxidation efficiency were investigated.

\section{Experiment part}

\subsection{Process description}

The on-site operation of ozone oxidation experiments were conducted at a steel-making plant in Tangshan, Hebei province. An ozone oxidation system was built, and sintering flue gas was extracted from the pipeline between the induced draft fan and the desulfurization tower at $30000 \mathrm{~m}^{3} / \mathrm{h}$. The temperature of flue gas was about $140^{\circ} \mathrm{C}$. The NO concentration was $70 \mathrm{mg} / \mathrm{m}^{3}$. As shown in figure $1, \mathrm{O}_{3}$ generated by an ozone generator (GUOLIN, CF-G-2-7kg) was injected into the flue gas

\footnotetext{
* Corresponding author: yangyx@gdj-tech.com
} 
by ozone feeding distributor at the inlet of the mixing chamber where $\mathrm{O}_{3}$ and flue gas were mixed thoroughly. The mixed flue gas resided in the system for $0.6 \sim 1.0 \mathrm{~s}$. Finally, the oxidized flue gas entered into the desulfurization tower to remove the $\mathrm{SO}_{2}$ and $\mathrm{NO}_{x}$ from the flue gas simultaneously.

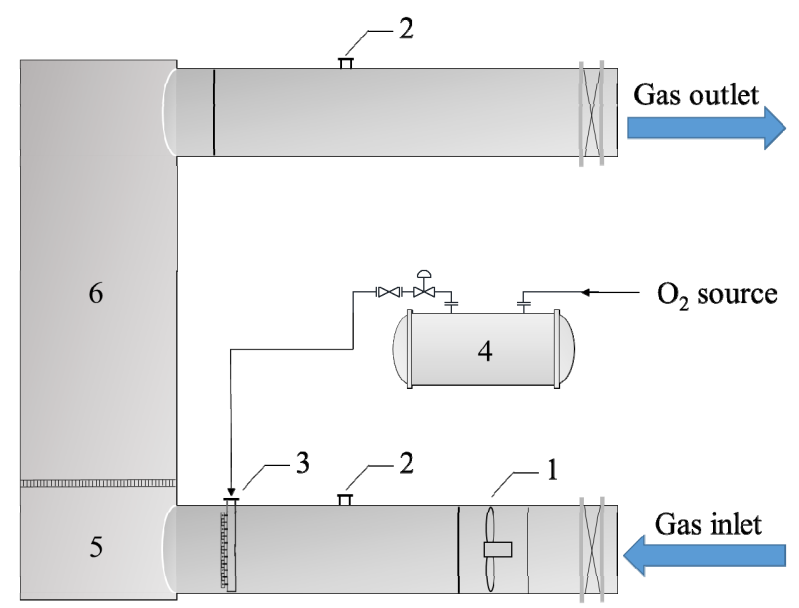

1- Axial flow fan; 2- Testing port;

3- Ozone feeding distributor; 4- Ozone generator; 5- Mixing chamber; 6- Oxidation chamber.

Fig. 1 Diagram of ozone oxidation system

\subsection{Generation of ozone}

The ozone generator generated $\mathrm{O}_{3}$ through dielectric barrier discharge (DBD) with an adjustable discharge power ranging from 13 to $45 \mathrm{~kW}$. $\mathrm{O}_{2}$ gas $(99.5 \%$ vol.) was used as the gas source of generator, and its rated consumption was $70 \mathrm{~kg} / \mathrm{h}\left(50 \mathrm{~m}^{3} / \mathrm{h}\right)$. The energy consumption of generator to generate $1 \mathrm{~kg} \mathrm{O}$ was 7.5 $\mathrm{kWh}$. The rated $\mathrm{O}_{3}$ concentration and $\mathrm{O}_{3}$ yield of generator were $148 \mathrm{mg} / \mathrm{L}\left(50 \mathrm{~m}^{3} / \mathrm{h}\right.$ ) and $7 \mathrm{~kg} / \mathrm{h}$ (with an adjustable range from 10 to $100 \%$ ) respectively.

\subsection{Evaluation of NO oxidation efficiency}

The $\mathrm{O}_{3}$ concentration at the outlet of ozone generator was monitored online by ozone concentration detector, and $\mathrm{O}_{3}$ yield was calculated by the control system of generator. The NO concentration at the inlet and outlet of ozone oxidation system was measured by an exhaust gas analyser (Testo 350). Based on the monitoring results, the NO oxidation efficiency can be estimated by equation (4).

$$
\eta_{N O}=\frac{[\mathrm{NO}]_{\text {in }}-[\mathrm{NO}]_{\text {out }}}{[\mathrm{NO}]_{\text {in }}} \times 100 \%
$$

In equation (4), $[\mathrm{NO}]_{\text {in }}$ and $[\mathrm{NO}]_{\text {out }}$ represent the $\mathrm{NO}$ concentration at the inlet and outlet of system respectively.

\section{Results and discussion}

\subsection{Influence of discharge power of ozone generator}

\subsubsection{Influence of discharge power on ozone concentration and yield}

As shown in figure 2, when the $\mathrm{O}_{2}$ flow rate was 30 $\mathrm{Nm}^{3} / \mathrm{h}$, the discharge power of ozone generator in the preheating stage was $12.9 \mathrm{~kW}$, while the concentration of generated $\mathrm{O}_{3}$ was $65 \mathrm{mg} / \mathrm{L}$ which was equivalent to $2.52 \mathrm{~kg} / \mathrm{h}$. With the increase of discharge power, $\mathrm{O}_{3}$ concentration and yield increased.

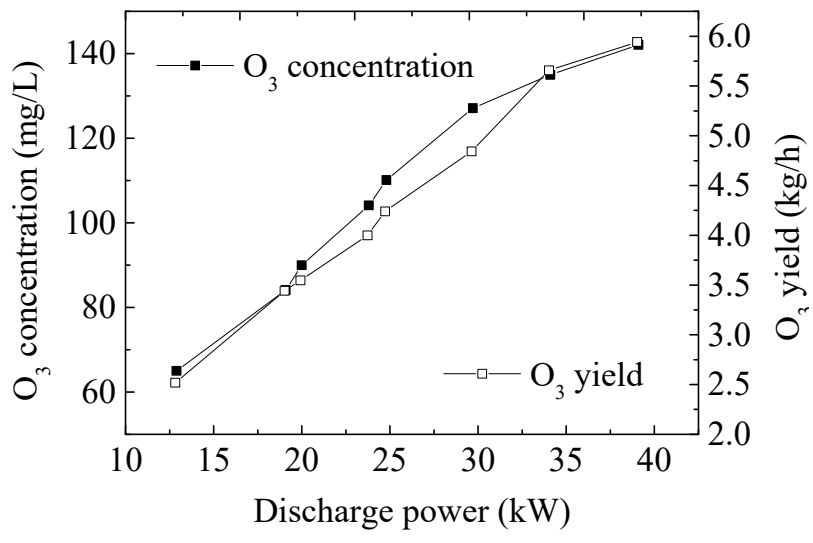

Fig. 2 Influence of discharge power on ozone concentration and yield

\subsubsection{Influence of discharge power on NO oxidation}

According to the previous section, the change of discharge power of ozone generator would result in the change of the generated $\mathrm{O}_{3}$ concentration. It is thus expected that NO oxidation was enhanced under high discharge powers due to the increased $\mathrm{O}_{3}$ concentrations. As shown in figure 3, NO oxidation efficiency increased along with the discharge power. When the discharge power increased from $12.9 \mathrm{~kW}$ to $29.7 \mathrm{~kW}, \mathrm{O}_{3}$ concentration increased correspondingly from $65 \mathrm{mg} / \mathrm{L}$ to $127.1 \mathrm{mg} / \mathrm{L}$, and $\mathrm{NO}$ oxidation efficiency increased from $70.8 \%$ to $87.7 \%$.

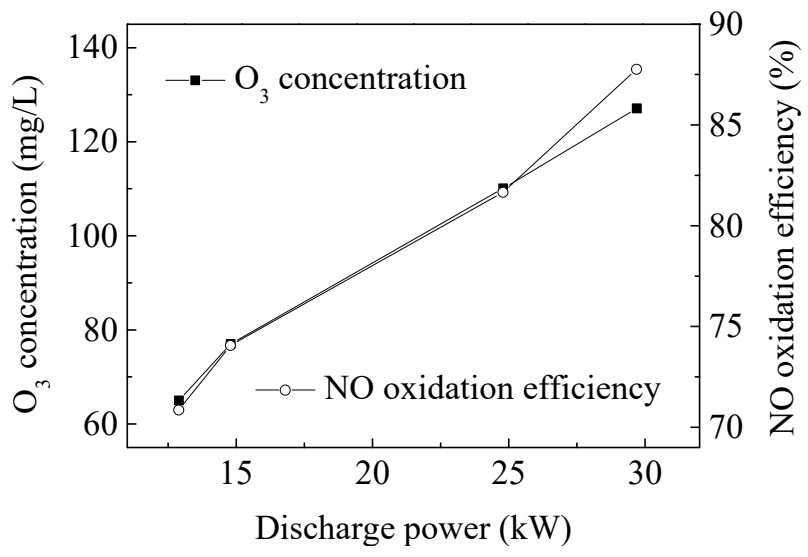

Fig. 3 Influence of discharge power on ozone concentration and $\mathrm{NO}$ oxidation efficiency

(The $\mathrm{O}_{2}$ flow rate is $30 \mathrm{Nm}^{3} / \mathrm{h}$.) 


\subsubsection{Influence of ozone dosage on NO oxidation}

To investigate the influence of $\mathrm{O}_{3} / \mathrm{NO}$ molar ratio on $\mathrm{NO}$ oxidation efficiency, $\mathrm{O}_{3}$ concentration at the outlet of ozone generator was converted into concentration in the flue gas. As shown in figure 4, there was a significantly positive correlation between NO oxidation efficiency and $\mathrm{O}_{3} / \mathrm{NO}$ molar ratio, and the increase of $\mathrm{O}_{3}$ dosage imposed a significant influence on $\mathrm{NO}$ oxidation efficiency. When the $\mathrm{O}_{3} / \mathrm{NO}$ molar ratio increased from 0.84 to 1.37 , NO oxidation efficiency increased correspondingly from $70.8 \%$ to $87.7 \%$.

It was observed that $\mathrm{NO}$ oxidation efficiency was $75 \%$ under the $\mathrm{O}_{3} / \mathrm{NO}$ molar ratio of 1 which was lower than the theoretical value indicated by equation (1). This could be ascribed to that $\mathrm{O}_{3}$ oxidized generated $\mathrm{NO}_{2}$ into high-valence nitrogen oxides (such as $\mathrm{NO}_{3}, \mathrm{~N}_{2} \mathrm{O}_{5}$, etc.) or reacted with other components in flue gas, which made some of $\mathrm{O}_{3}$ not be used for $\mathrm{NO}$ oxidation.

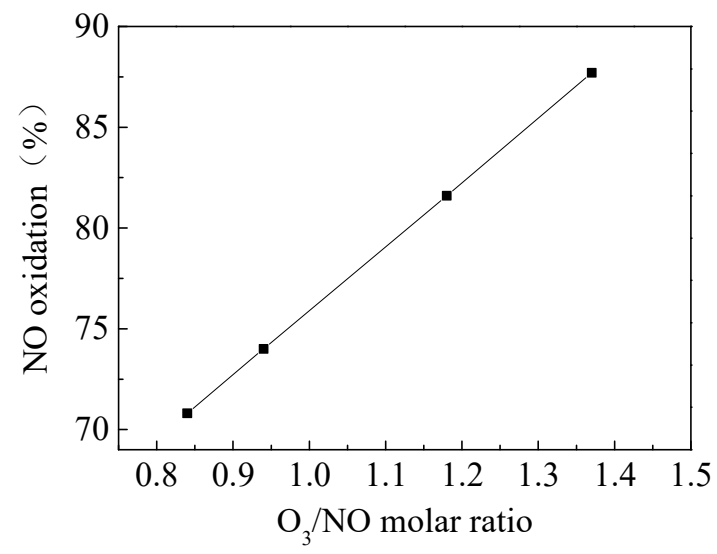

Fig. 4 Influence of ozone dosage on NO oxidation efficiency (The $\mathrm{O}_{2}$ flow rate is $30 \mathrm{Nm}^{3} / \mathrm{h}$.)

\subsection{Influence of oxygen flow rate of ozone generator}

\subsubsection{Influence of oxygen flow rate on ozone concentration and yield}

Figure 5 indicated a significantly negative correlation between $\mathrm{O}_{3}$ concentration and $\mathrm{O}_{2}$ flow rate, while $\mathrm{O}_{3}$ yield was positively associated with $\mathrm{O}_{2}$ flow rate. Within a range of $\mathrm{O}_{2}$ flow rate from $28.6 \mathrm{Nm}^{3} / \mathrm{h}$ to $45.2 \mathrm{Nm}^{3} / \mathrm{h}$, the $\mathrm{O}_{3}$ generation rate increased with $\mathrm{O}_{2}$ flow rate, leading to a higher $\mathrm{O}_{3}$ yield. However, the generated $\mathrm{O}_{3}$ gas was diluted by the increased feed of $\mathrm{O}_{2}$ gas leading to a reduced observed concentration.

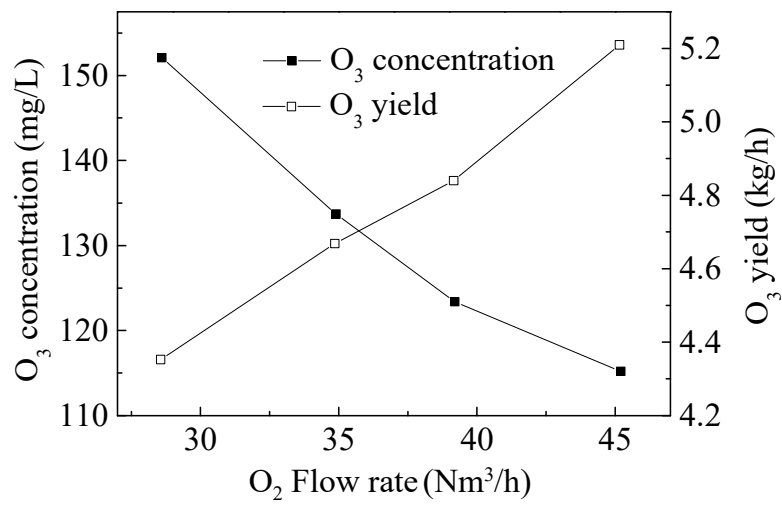

Fig. 5 Influence of oxygen flow rate on ozone concentration and yield

(The discharge power is $30 \mathrm{~kW}$.)

As shown in figure $6, \mathrm{O}_{3}$ yield increased with discharge power which was consistent with the above conclusion. Besides, $\mathrm{O}_{3}$ yield of different discharge power increased gently with $\mathrm{O}_{2}$ flow rate.

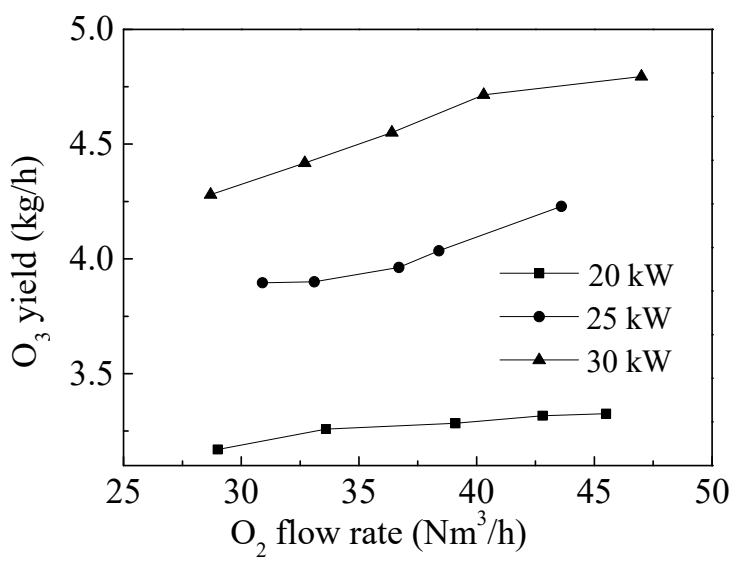

Fig. 6 Relationship between oxygen flow rate and ozone yield under different discharge power

\subsubsection{Influence of oxygen flow rate on NO oxidation}

In order to investigate the influence of $\mathrm{O}_{2}$ flow rate on NO oxidation efficiency, $\mathrm{O}_{2}$ flow rate was increased from $34.9 \mathrm{Nm}^{3} / \mathrm{h}$ to $45.2 \mathrm{Nm}^{3} / \mathrm{h}$ which resulted in a decrease in $\mathrm{O}_{3}$ concentration from $133.7 \mathrm{mg} / \mathrm{L}$ to 115.2 $\mathrm{mg} / \mathrm{L}$. However, as shown in figure 7, NO oxidation efficiency changed slightly and sustained between $85 \sim 88 \%$. When $\mathrm{O}_{2}$ gas was used as the gas source of ozone generator, numerous studies have shown an ability of DBD to generate many kinds of reactive species, such as $\mathrm{O}_{3}, \mathrm{O}_{2}, \mathrm{O}$, e, etc. With the increase of $\mathrm{O}_{2}$ flow rate, the generated $\mathrm{O}$ and other reactive radical in unit volume increased which also had oxidation to NO. Therefore, the change of $\mathrm{O}_{2}$ flow rate exhibited little influence on NO oxidation efficiency despite of the decrease in $\mathrm{O}_{3}$ concentration. 


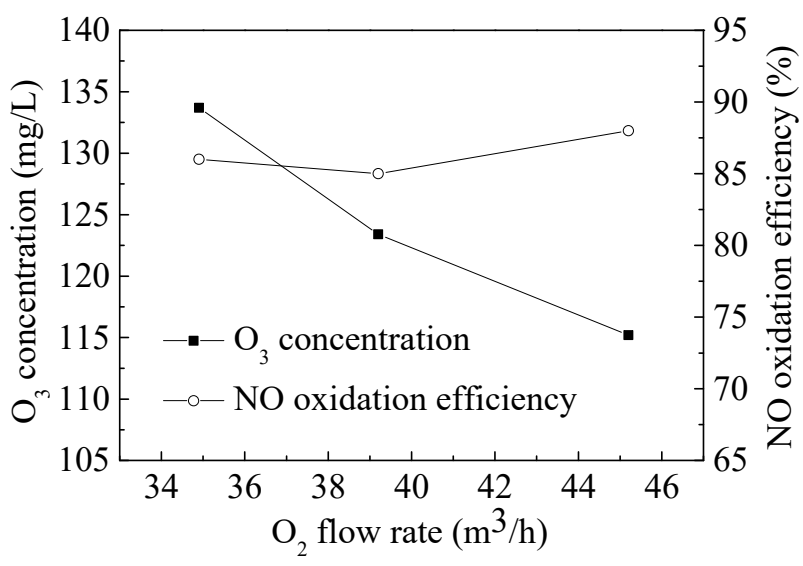

Fig. 7 Influence of oxygen flow rate on ozone concentration and NO oxidation efficiency

(The discharge power is $30 \mathrm{~kW}$.)

\subsection{Assessment of NO oxidation energy consumption}

When inlet $\mathrm{NO}$ concentration was $70 \mathrm{mg} / \mathrm{m}^{3}$ and $\mathrm{O}_{3} / \mathrm{NO}$ molar ratio was 1 , the NO oxidation efficiency was $75 \%$. In this case, the energy consumption of ozone generator to generate $1 \mathrm{~kg} \mathrm{O}_{3}$ was $7.5 \mathrm{kWh}$ which was equivalent to $62.5 \mathrm{~g} / \mathrm{kWh}$. According to these data, the average oxidation energy consumption of each $\mathrm{NO}$ molecule was $0.05 \mathrm{eV}$ which was much lower than that of $30 \mathrm{eV}$ in discharge plasma oxidation. It could be concluded that ozone oxidation denitration process was feasible and economical.

\section{Conclusions}

In this investigation, the influence of discharge power and $\mathrm{O}_{2}$ flow rate of ozone generator on $\mathrm{O}_{3}$ concentration, $\mathrm{O}_{3}$ yield and $\mathrm{NO}$ oxidation were investigated. The results indicated that $\mathrm{O}_{3}$ concentration, $\mathrm{O}_{3}$ yield and $\mathrm{NO}$ oxidation efficiency increased along with the discharge power under the same $\mathrm{O}_{2}$ flow rate and inlet $\mathrm{NO}$ concentration. There was a significantly positive correlation between $\mathrm{NO}$ oxidation efficiency and $\mathrm{O}_{3} / \mathrm{NO}$ molar ratio, and the increase of $\mathrm{O}_{3}$ dosage imposed a significant influence on NO oxidation efficiency. These test results showed that applying ozonation denitration process to dealing with sintering flue gas could achieve a NO oxidation efficiency higher than $90 \%$.

Besides, under the same discharge power and inlet $\mathrm{NO}$ concentration, with the increase of $\mathrm{O}_{2}$ flow rate, $\mathrm{O}_{3}$ concentration decreased gradually while $\mathrm{O}_{3}$ yield increased gradually. However, little effect of $\mathrm{O}_{2}$ flow rate on NO oxidation efficiency was observed. In the application of ozone oxidation denitration engineering, when the $\mathrm{O}_{2}$ was supplied in a certain amount, we should improve NO oxidation efficiency by adjusting the discharge power of ozone generator. But considering some of $\mathrm{O}_{3}$ may not be used for $\mathrm{NO}$ oxidation in practical engineering application, $\mathrm{O}_{3}$ dosage should be moderately higher than the theoretical value under the reasonable economic consideration.

\section{Acknowledgements}

The authors gratefully acknowledge financial support by Science and Technology Plan Project of Guangdong Province, China (No. 2017B090901057).

\section{References}

1. H.Y. Jiang, Shandong Chemical Industry 45, 150 (2016)

2. Z.L. Liu, Petroleum Refinery Engineering 42, 23(2012)

3. Y.S. Mok, H. Lee, Fuel Process. Technol 87, 591 (2006)

4. Z.H. Wang, J.H. Zhou, J.R. Fan, Y.Q. Zhu, Z.C. Wen, J.Z. Liu, K.F. Cen, Fuel Process. Technol 88, 817 (2007)

5. Z.H. Wang, J.H Zhou, J.R. Fan, K.F Cen, Energy Fuels 20, 2432 (2006) 